\title{
Morele stress in tijden van corona \\ (n)
}

Wat is goede zorg als deze overspoeld wordt door covid-patiënten? Zorgverleners raken soms gefrustreerd als zij niet kunnen voldoen aan hun eigen ethische normen. 'Praat erover, en accepteer dat je soms niet meer kunt doen dan je hebt gedaan.'

tekst Margot Hamel illustratie Bernet Ragetli

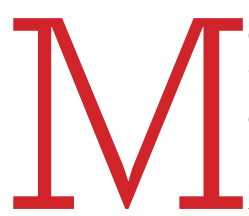
evrouw Van Slochteren (79) ligt op de palliatieve covid19-unit van het ziekenhuis. Ze is positief getest op covid-19. Na 10 dagen is ze aan de beterende hand. Helaas is mevrouw al langere tijd delirant. Ze is inmiddels 'te goed' voor het ziekenhuis, maar kan niet naar huis, en dus moet ze revalideren in het verpleeghuis.

Dit soort kwesties levert een dilemma op, vertelt Nicolette Gunnink-Boonstra. Normaal is zij palliatief consulent in het Amsterdamse OLVG, locatie Oost, maar in coronatijd stond ze op de palliatieve covid-19-unit. 'Patiënten met een delier kunnen zich beter oriënteren als er naasten op bezoek komen. Op onze palliatieve unit kon dat, al was het maar een keer per dag. In het verpleeghuis gold echter een strikt bezoekverbod. Dat zou het herstel van mevrouw niet bevorderen. Maar ja, de kans op infecties is in het ziekenhuis reëel. Uiteindelijk is mevrouw naar het verpleeghuis gegaan, tegen de wens van de familie in. Daar kan ik nu nog buikpijn van krijgen.'

\section{Morele stress}

Dit is een voorbeeld van morele stress. 'Morele stress is het wrange gevoel dat zorgverleners ervaren wanneer zij de zorg die zij willen bieden, niet in de praktijk kunnen brengen', vertelt Yvonne Denier, zorgethicus van de Vlaamse koepelorganisatie Zorgnet-Icuro en hoofddocent ethiek aan de KU Leuven. 'Ze
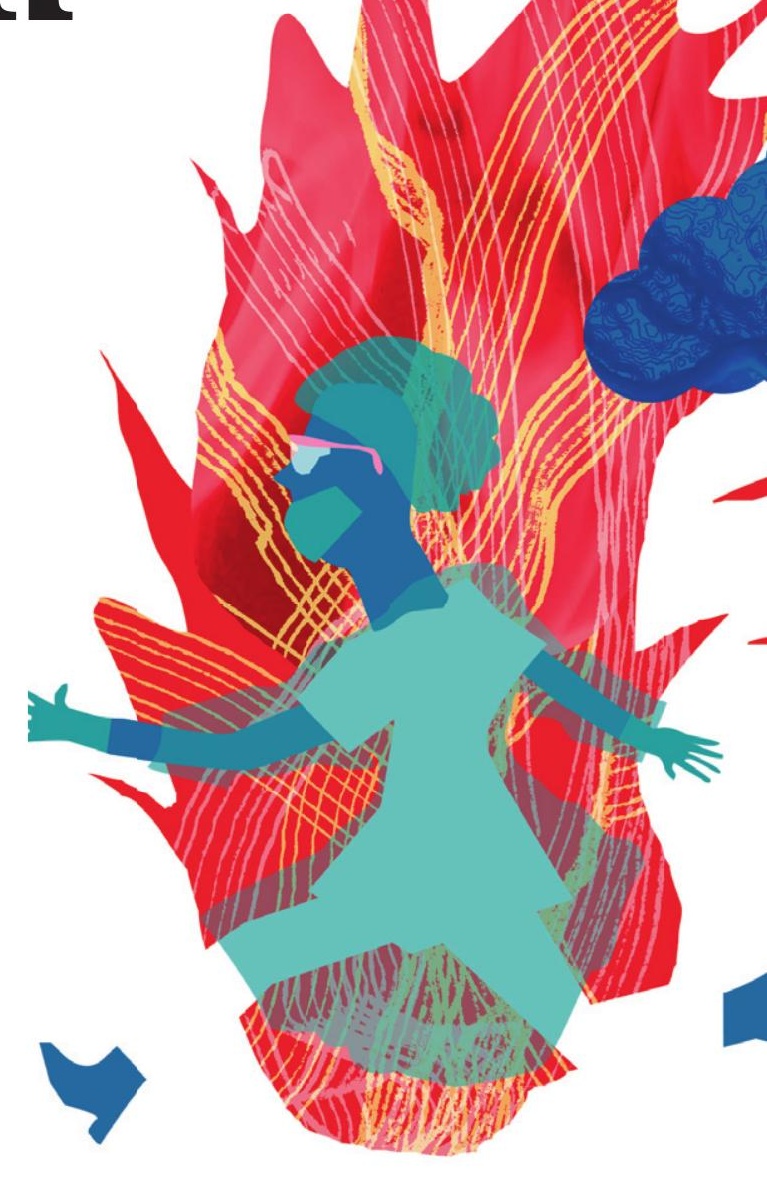

hebben het gevoel dat er iets niet klopt en dat de zorg die ze bieden niet meer overeenstemt met hun eigen waarden, met wat 'goed' is om te doen. Ze willen persoonsgerichte zorg bieden, maar door de omstandigheden lukt dat niet.'

Toen covid-19 de zorgsector overspoelde, steeg de gemiddelde morele 
CLL van loghum

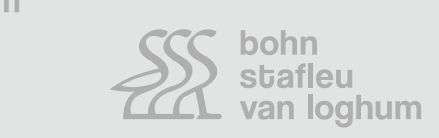

van loghum

CSS bohn

8 stafleu

van loghum
Pl stafleu

van loghum

SSS bohn

van loghum

SCS bohn

stafleu

van loghum

CSS bohn

8 stafleu

van loghum

SSS bohn

$8 \int$ stafleu

van loghum

8SS lohn

L van loghum

SSS bohn

L van loghum

SCS bohn stafleu

II van loghum

SCS bohn

8) stafleu

van loghum

CSS bohn

van loghum

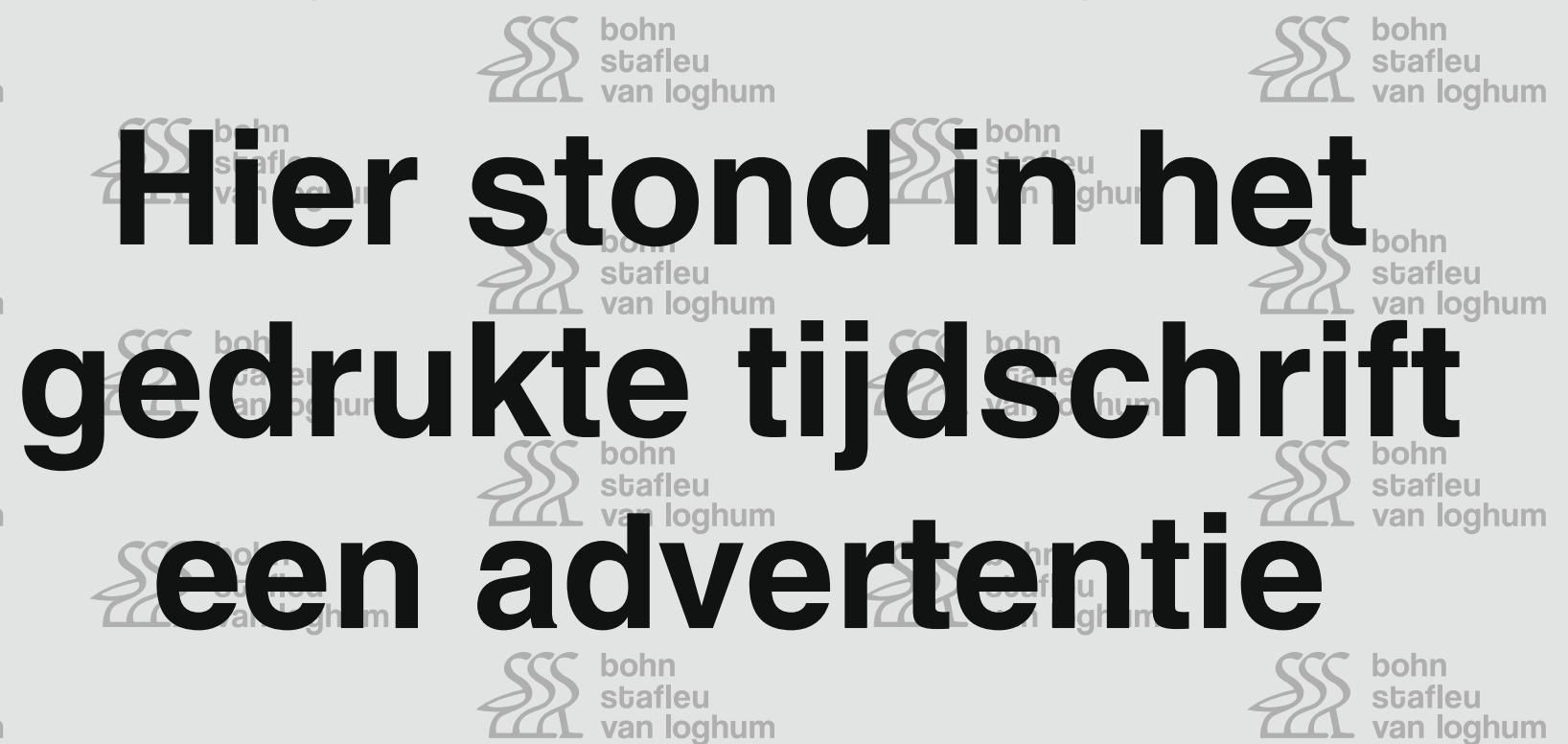

SCS bohn stafleu

van loghum

CSS bohn

Stafleu van loghum

SSS $\begin{aligned} & \text { bohn } \\ & \text { stafleu }\end{aligned}$

SCS bohn stafleu

I van loghum

CCS bohn

-) stafleu

van loghum

CSS bohn

bohn
stafleu

I van loghum

SSS $\begin{aligned} & \text { bohn } \\ & \text { stafleu }\end{aligned}$

van loghum

CSS bohn

SCS bohn

bohn
stafleu

van loghum

SSS bohn

CL van loghum

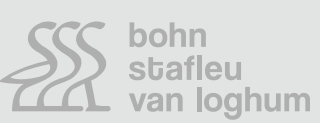

CSS bohn

8) stafleu

van loghum
CL van loghum

$\iint$ stafleu

I van loghum

CSS bohn

S) stafleu

CL van loghum

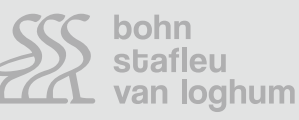

SSS bohn

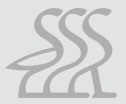

SS

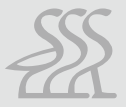

SSS

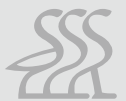

CSS bohn

$8 \int$ stafleu

van loghum

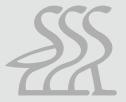

CSS bohn

stafleu

van loghum

SSR

CSe bohn

8) stafleu

van loghum

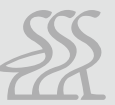

SSS bohn

van loghum

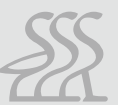




\section{Er voor de patiënt zijn}

Waar zorgverleners ook last van kunnen hebben, is de botsing tussen hun klinisch-ethische normen en de maatschappelijke normen, legt Denier uit. 'Verpleegkundigen hebben een klinische-ethische zorgstandaard waar hun zorgverlening aan moet voldoen. Zo willen zij er zijn voor de patiënt als die angstig is, of als hij bekommernissen heeft. Vaak zijn ze fysiek dichtbij, pakken een hand of troosten iemand met een knuffel. Daar staan in coronatijd de strikte veiligheidsmaatregelen tussen die de volksgezondheid moeten helpen, de maatschappelijke norm. Door de beschermende kleding, het masker en de bril voldoen ze echter niet aan hun ethische zorgstandaard van warme, persoonsgerichte zorg. Dat wordt versterkt door het voorschrift de patiënt bij voorkeur niet aan te raken.

\section{nursing/congressen}

\section{DE DAG VAN DE ZORGPROFESSIONAL}

Leer hoe je als verpleegkundige goed in je vel blijft zitten tijdens de Dag van de Zorgprofessional, op 28 augustus 2020 in Ede. Op deze dag ontdek je hoe je mentaal fit wordt, wat je nodig hebt voor meer grip op de werkdruk, hoe je rust creëert in stressvolle situaties en op welke manier je meer energie uit je werk haalt. Meer informatie: nursing.nl/congressen/zorgprofessional.

zone gehaald. Ze moeten op het randje van hun kunnen presteren, en dat is voor sommigen wrang.'

\section{En wat nu?}

Volgens Yvonne Denier zijn er geen standaardoplossingen om met morele stress om te gaan. 'Ik denk wel dat organisaties die al langer met ethiek of moreel beraad bezig zijn, daar nu de vruchten van plukken. Hoe meer ruimte je aan ethiek en ethisch overleg geeft, hoe makkelijker het de zorgverleners afgaat om morele stress ter sprake te brengen. Erover

\section{Invallers op de ic voelden zich daar onvoldoende deskundig, ook dat kan morele stress opleveren}

Ook het verminderde contact met de familie zorgt voor een botsing met hun norm van goede zorg.'

\section{Onveilig gevoel}

Naast de warme zorg kunnen zorgverleners niet de kwalitatief beste zorg leveren die ze gewend zijn. Denier: 'Verpleegkundigen verlieten hun vertrouwde afdeling om bijvoorbeeld op de intensieve zorgen bij te springen. Gewoonlijk voel je je bekwaam in je eigen specialisme, maar plots moet je in een ander domein inspringen. Dat voelt onveilig, je twijfelt of je het wel aankunt. Ik sprak invallers op intensieve zorgen die zeiden van 'Tja, het duurt toch wel een paar jaar voordat je je hier echt deskundig genoeg voelt, wat kan ik hier nu bijdragen?' Mensen worden uit hun professionele comfort-

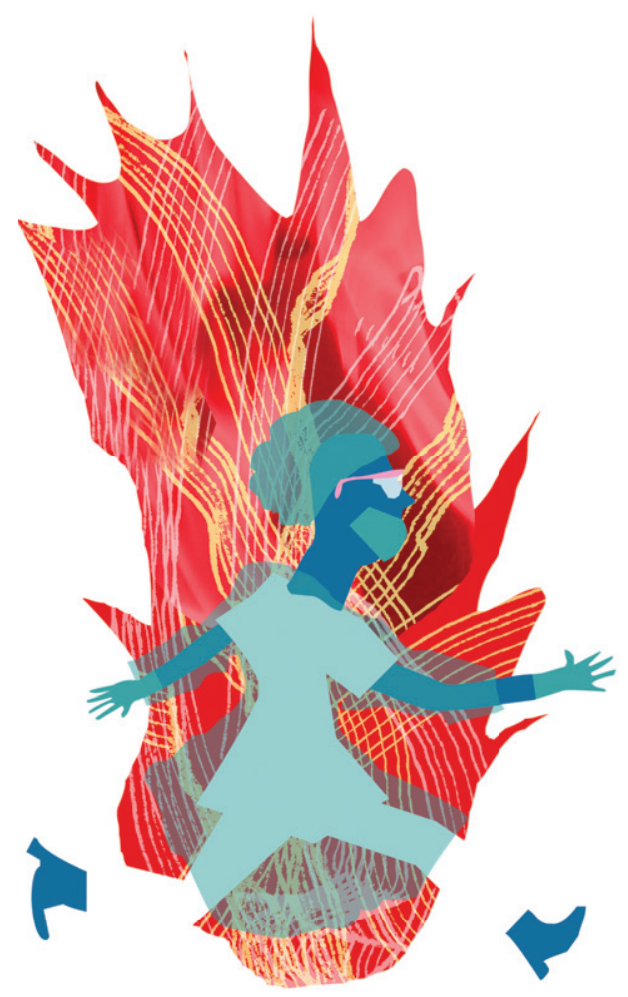

praten is zo belangrijk! Na deze eerste coronagolf is het goed om als team op de rem te trappen en samen stil te staan bij zaken waar collega's moeite mee hadden. Wat was normaal in de situatie, wat was achteraf niet nodig geweest? Virologen zeggen dat er een nieuwe coronagolf zal komen. Dus wat kunnen we leren om onze morele veerkracht ${ }^{2}$ te vergroten zodat we er later beter mee kunnen omgaan? En realiseer je, zegt Denier: er is veel moois bedacht in de zorg. De foto's op de isolatiejassen voor een menselijk gezicht, het videobellen in de woonzorgcentra, het bellen met een babyfoon met daartussen slechts een raam, het zijn allemaal pogingen om de menselijke waardigheid en warmte enigszins terug te brengen. Bedenk dat ook in het normale zorgleven niet alles zorgeloos verloopt. 'We proberen het iedere dag zo goed mogelijk te doen, ook in deze coronatijd. Die gedachte kan rust geven. Sta daar als team bij stil. Wat deden we vandaag goed? Onthoud daarbij dat de ideale oplossing niet bestaat.'

\footnotetext{
Noten

1 In de Tweede Barometer van mei deden ruim 660 verpleegkundigen (20\%) mee op een totaal van 3300 respondenten, naast medisch specialisten, zorgkundigen, en vele andere beroepsgroepen in de zorg. In Nederland ervaren sinds de coronauitbraak 7 van de 10 collega's meer psychische belasting dan gewoonlijk. De belasting is het grootst in verpleeghuizen en op cohort-afdelingen. De meest voorkomende klachten zijn vermoeidheid (vooral hoog op ic- en cohort-afdelingen), onzekerheid, stress, machteloosheid, rusteloosheid en slapeloosheid. Bron: Wapenaar J. V\&VN: 'Veel verpleegkundigen door coronacrisis zwaarder psychisch belast'. www.nursing.nl $>1$ mei 2020

2 Van Pelt E. Van morele stress naar morele veerkracht. Nursing april 2019.
} 